\title{
Erratum
}

\section{Effect of lesion level on the orthotic gait performance in individuals with complete paraplegia}

N Kawashima, D Taguchi, K Nakazawa and M Akai

Spinal Cord (2006) 44, 522. doi:10.1038/sj.sc.3101941

Correction to: Spinal Cord (2006) 44, 487-494. doi:10.1038/sj.sc.3101916; published online 21 March 2006

Owing to a typesetting error, Figure 4 in the above paper was published inaccurately. A corrected figure is shown below.
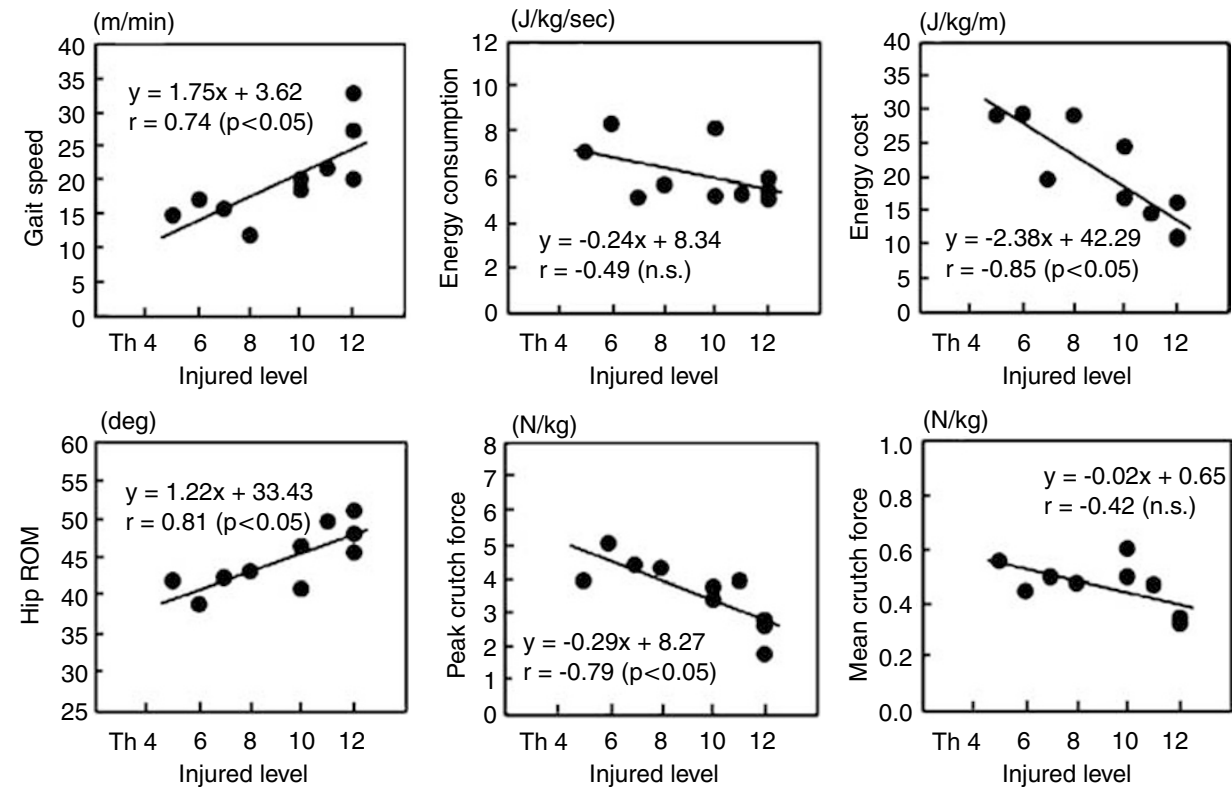

Figure 4 Effects of the level of injury on gait speed, cadence, stride length, energy consumption, energy cost, and hip range of motion. The lines indicate the linear regression lines of the level of injury against each parameter 